\title{
Clinical management of severe active ulcerative colitis in the TNF- $\alpha$ inhibitors era
}

\author{
Andrea Calafiore, Fernando Rizzello, Chiara Praticò, Paolo Gionchetti, Carlo Calabrese, Giuseppina Liguori, \\ Massimo Campieri
}

Department of Clinical Medicine, IBD Unit, University of Bologna, S. Orsola-Malpighi Hospital, Bologna, Italy

\begin{abstract}
Ulcerative colitis (UC) is a chronic inflammation of the coli mucosa clinically characterized by bloody diarrhea, abdominal pain and other systemic symptoms. The onset, as well as subsequent relapses, may occur with varying degrees of clinical and endoscopic activity and extent of disease. The clinical and endoscopic activity varies from mild to severe, while the extent of disease, without interruption, may involve from the rectum up to the entire colon. The severe form, when not properly and promptly treated, can be life-threatening and may determine various complications requiring urgent surgical treatment. Early recognition of severe forms, their treatment and patient monitoring can reduce morbidity and mortality, and improve surgical outcome. Since the 1950s, systemic corticosteroids have been the first-line treatment in severe active UC. Today, appropriate patient monitoring, and recognition of clinical, radiological and laboratory findings indicative of steroid failure guide the clinician in the use of immunomodulatory drugs or suggest indications for surgery. The aim of our study is to review the more recent data and guidelines that could be useful in clinical practice for the management of severe UC.
\end{abstract}

\section{Introduction}

Today there is still no universally accepted definition of severe ulcerative colitis. The definition most used in clinical practice is that based on the criteria of Truelove and Witts ${ }^{1,2}$ who were the first to define as severe the form characterized by 6 or more mucohematic discharges over a $24-\mathrm{h}$ period and one or more of the following: body temperature $>37.8^{\circ} \mathrm{C}$; heart rate $>90 \mathrm{bpm}$; hemoglobin $>10.5 \mathrm{~g} / \mathrm{dL}$; erythrosedimentation rate $>30 \mathrm{~mm} / \mathrm{h}$. The clinical severity must be confirmed by a severe endoscopic profile defined as the presence of spontaneous bleeding, deep ulceration and mucosal appearance ${ }^{3}$ (Table 1).

Correspondence: Andrea Calafiore, Department of Clinical Medicine, IBD Unit, University of Bologna, S. OrsolaMalpighi Hospital, via Massarenti 9, 40138 Bologna, Italy. Tel. +39.051.6364122 - Fax: +39.051.6364129.

E-mail: calafiore.a@gmail.com

Key words: ulcerative colitis, treatment, infliximab, surgery, management.

Conflict of interests: the authors declare no potential conflict of interests.

This work is licensed under a Creative Commons Attribution NonCommercial 3.0 License (CC BY-NC 3.0).

CCopyright A. Calafiore et al., 2013

Licensee PAGEPress, Italy

Italian Journal of Medicine 2013; 7:272-277

doi:10.4081/itjm.2013.272
Even though total colonoscopy is considered safe in the hands of expert operators, and can provide useful information to make a correct evaluation of the extent and severity of the disease, the risks of complications induced by the procedure are still too high and, in the end, similar information can be obtained by more limited examination. ${ }^{4}$ Careful sigmoidoscopy performed without preparatory procedures and with the minimum insufflation of air can be sufficient to obtain all the information needed, even in cases of a suprainfection of Clostridium difficile or cytomegalovirus, and can reduce the risk of acute dilation or perforation of the colon.

The main role of the endoscopy must remain that of guiding the decision-making process in those patients who present clinical aspects that are not clear or who achieve a partial response to medical treatment for whom surgery should be considered. Such an approach is also confirmed from the most recent guidelines proposed by the European Crohn's Colitis Organization (ECCO) and by the Italian Group for Inflammatory Bowel Disease (IGIBD), ${ }^{5,6}$

\section{Monitoring and prognostic factors}

The patient with severe active ulcerative colitis (UC) must be hospitalized and evaluation must include immediate consultation with doctors from the Surgical Unit. The daily evaluation of the patient must be complete and should include measurement of body temperature, heart rate, number of discharges over a 24-h period, together with consistency of the 
stool and the presence of blood. Furthermore, the guidelines suggest daily blood counts, erythrocyte sedimentation rate, $\mathrm{C}$-reactive protein, electrolytes and albuminemia. Careful clinical and laboratory evaluation aims to identify factors capable of providing early prediction of any possible inefficacy of traditional therapy. In fact, the introduction of new therapies for the treatment of severe forms that do not respond to standard therapy risks delaying an indication for surgery, with all the consequences that could result from this.

Travis and colleagues have demonstrated that after three days of therapy, $85 \%$ of patients with more than 8 discharges a day or 3-8 discharges a day associated with blood levels over $45 \mathrm{mg} / \mathrm{L}$ by polymerase chain reaction will not respond to medical treatment. ${ }^{7}$

Similarly, Lennard-Jones demonstrated that fever, tachycardia, hypoalbuminemia, a high number of discharges over a 24 -h period and mucosal appearances on endoscopy or dilation of the colon on abdominal echography are early signs of treatment failure. ${ }^{8} \mathrm{Ab}$ dominal X-ray is essential to reveal disease-related complications (e.g. relaxation of the colon, intestinal occlusion or perforation) and to show radiological signs known to be risk factors for colectomy. Furthermore, abdominal X-ray provides a series of other data such as the extent of disease, the presence of deep ulcers and of mucosal appearances. Caprilli and colleagues and Chew and colleagues have shown that the evaluation of the extent and the distribution of endoluminal gas (evaluated through abdominal X-ray), the presence of dilation of the small intestine and dilation (6 $\mathrm{cm}$ diameter) of the upper colon are significantly associated with failure of medical treatment and with the need for surgical intervention. ${ }^{9,10}$ Early identification of these parameters determines the need to intensify or to modify the medical treatment, even in the absence of clinical criteria of severity or in the presence of a partial clinical response (Table 2). ${ }^{7-10}$

\section{Treatment}

Severe UC is a serious and potentially life-threatening condition. Treatment with high-dose steroids and early indication for surgery, proposed by Truelove and Witts in 1954, have dramatically reduced mortality from $31-61 \%{ }^{11}$ to $3 \%,{ }^{12}$ reaching zero in reference centers. Over recent years, the introduction of new drugs have once again led to surgical intervention being postponed, often well over the 7-10 days indicated by Truelove and Witts.

The use of immunosuppressives or biological drugs in patients with UC refractory to steroids requires accurate patient monitoring on the part of the medical/surgical team. The ECCO guidelines confirm the importance of the work of this team, suggesting that possible indications for surgery should be discussed at every stage of the severe form of disease (statement 5F, 5).

Table 1. Clinical scoring of ulcerative colitis.

\begin{tabular}{lcccc}
\hline & Slight & Moderate & Severe & Fulminating \\
\hline No. discharges & $<4$ & $4-6$ & 6 & 10 \\
\hline Blood in stools & Intermittent & $\leftrightarrow$ & Frequent & Continuous \\
\hline Temperature, ${ }^{\circ} \mathrm{C}$ & Normal & $\leftrightarrow$ & $>37.5^{\circ} \mathrm{C}$ & $>37.5^{\circ} \mathrm{C}$ \\
\hline Heart rate & Normal & $\leftrightarrow$ & $>90 \mathrm{bpm}$ & $>90 \mathrm{bpm}$ \\
\hline Hemoglobin & Normal & $\leftrightarrow$ & $<75 \%$ of normal & Requiring blood transfusion \\
\hline ESR & $<30$ & $\leftrightarrow$ & 30 & $>30$
\end{tabular}

ESR, erythrocyte sedimentation rate. Modified from Truelove and Witts, $1954 .{ }^{1}$

Table 2. Prognostic factors for failure of medical therapy.

\begin{tabular}{|c|c|}
\hline References & Factors \\
\hline Travis et al..$^{7}$ & $\geq 8$ blood discharges/die or $3-8$ blood discharges with PCR $>45 \mathrm{mg} / \mathrm{L}$ after 3 days of e.v. steroids ( $85 \%$ failure rate) \\
\hline Lennard-Jones ${ }^{8}$ & $\begin{array}{l}\text { Fever, tachycardia, hypoalbuminemia, high no. of discharges in } 24-\mathrm{h} \text { period+endoscopic evidence of severity or with } \\
\text { signs of relaxation of the colon from abdominal X-ray }\end{array}$ \\
\hline $\begin{array}{l}\text { Capirilli et al. }{ }^{9} \\
\text { Chew et al. }{ }^{10}\end{array}$ & Abdominal X-ray with signs of dilation of the small intestine and relaxation of the colon (diameter $>6 \mathrm{~cm})$ \\
\hline
\end{tabular}




\section{Corticosteroids}

The use of corticosteroids in severe UC was introduced for the first time by Truelove and colleagues in 1954. In a comparison of different doses of hydrocortisone with placebo, approximately $75 \%$ of patients in the group treated with cortisone showed clinical improvement or remission compared with $41 \%$ of controls $(\mathrm{P}<0.001)$. Also, the response to steroid was similar both in cases of disease onset and in cases of relapse, even though patients in the first category showed a better response than those who relapsed ( $\mathrm{P}<0.001$ vs $\mathrm{P}<0.2) .{ }^{1}$

In 1974, Truelove and Jewell introduced the socalled intensive endovenous regimen. ${ }^{2}$ In this study, 49 patients with severe UC were treated with prednisolone 21-phosphate $0.75-1 \mathrm{mg} / \mathrm{kg} / \mathrm{die}(60 \mathrm{mg} / \mathrm{die})$, topical hydrocortisone, antibiotics, liquid supplementation, and electrolytes and fasting. Treatment lasted five days after which those patients who achieved disease remission swopped to oral steroids. In cases of absence of or poor clinical improvement, the patient was sent forward for surgery. The 5-day treatment was efficacious in $73 \%$ of patients. Prolonged treatment with steroids did not demonstrate any additional benefit in terms of clinical condition but there was, however, an increase in pre- and postoperative complications. This finding was recently the subject of discussion among some observers who demonstrated the efficacy of prolonged periods of treatment (7-10 days) to recover response in some patients. Furthermore, Bossa and colleagues have compared continuous infusion of methylprednisolone with bolus infusion and showed similar efficacy and safety. ${ }^{13}$ Even though minor efficacy was shown, administration of steroids in a single morning dose is currently recommended, aimed at respecting the circadian cycle of the steroid and of reducing the steroid-associated side effects. A fraction of the daily dose during the day is still shown to be useful in clinical practice in a variety of circumstances. In fact, some patients remain symptomatic with single administration of treatment, above all if they experience night discharges.

The guidelines recommend the use of full dose of steroid in order to reduce the phenomena of steroid-resistance and to begin scaling dosage only after obtaining complete clinical response. There are no precise rules concerning the progressive reduction of steroid other than that this must be done gradually. Patient response to the drug, any possible side effects and previous use of steroid can all guide the physicians' choice.

In patients in whom a rapid response to steroid treatment is observed, it is possible to scale down the steroid by 5 or $10 \mathrm{mg}$ each week, while dosage should be scaled down more gradually in patients who expe- rience a slower clinical response or who have already relapsed after suspending steroid treatment.

\section{Fasting}

Numerous studies have shown that fasting does not modify the outcome of a severe attack of ulcerative colitis. ${ }^{14}$ Nevertheless, fasting is obligatory in cases of severe $\mathrm{UC}$ with complications (e.g. radiological evidence of relaxation of the colon, imminent megacolon, clinical data and/or radiological evidence of intestinal occlusion).

If on the one hand fasting achieves a partial reduction in the number of discharges over the 24-h period, on the other hand oral food intake ensures physiological nutrition of the mucosa that could favor a better response to medical treatment.

\section{Antibiotics}

The role of antibiotics in the treatment of severe $\mathrm{UC}$ is a subject of controversy. Numerous studies have failed to show a role for antibiotics [endovenous (e.v.) metronidazole or ciprofloxacin] as adjuvant therapy to corticosteroids ${ }^{15,16}$ to increase their efficacy. Similarly, oral vancomicine at a dose of $500 \mathrm{mg}$ q.i.d. was not shown to be superior to placebo in patients with moderate or severe UC treated with prednisone. ${ }^{17}$ In another controlled study, oral tobramicine at a dose of $120 \mathrm{mg}$ t.i.d. associated with prednisolone 30-60 $\mathrm{mg} / \mathrm{die}$ showed remission rates of $70 \%$ in the group treated with antibiotics and of $43 \%$ in the placebo group $(\mathrm{P}=0.008) .{ }^{18}$ Finally, oral rifaximine $400 \mathrm{mg}$ b.i.d. significantly reduced the number of discharges in a 24-h period and the presence of blood in the stools in patients with steroid-refractory severe UC with respect to placebo. ${ }^{19}$ In severe forms of UC, often associated with sepsis from bacterial translocation, if antibiotics do not improve the efficacy of steroids, wide-spectrum antibiotic therapy is widely used.

ECCO guidelines include the use of triple antibiotic therapy (amoxicillin $500 \mathrm{mg}$ t.i.d., tetracycline $500 \mathrm{mg}$ t.i.d. and metronidazole $500 \mathrm{mg}$ t.i.d.) among those therapies the efficacy of which still remains to be established with any certainty. ${ }^{5}$

\section{Cyclosporine}

Patients who have demonstrated only a partial response to maximal treatment with systemic corticosteroids could be candidates to receive further treatment with e.v. cyclosporine. Lightiger and Present $^{20}$ evaluated the efficacy of e.v. cyclosporine at a dose of $4 \mathrm{mg} / \mathrm{kg} / \mathrm{die}$ in severe colitis resistant to steroid treatment in a controlled study with placebo. 
Nine of the 11 patients treated with cyclosporine experienced an improvement in their clinical condition after an average of seven days. This study was interrupted for ethical reasons because of the clear superiority of cyclosporine with respect to placebo; the study was never repeated. However, the small number of patients enrolled limited the value of the study, as indicated in many meta-analyses. In a subsequent study, cyclosporine was compared with methylpredinisolone at a fixed dose of $40 \mathrm{mg} / \mathrm{die}$ and showed the same efficacy as the previous study. ${ }^{21}$

Finally, Van Assche compared two different doses of cyclosporine ( $2 \mathrm{mg} / \mathrm{kg} / \mathrm{die} v s 4 \mathrm{mg} / \mathrm{kg} / \mathrm{die})$ obtaining the same efficacy but fewer side effects in the group treated with the lower dose. ${ }^{22}$ Drug efficacy, confirmed also by numerous open studies, is nevertheless counterbalanced by its side effect. ${ }^{23,24}$

Arts and colleagues have reported data of the series with the biggest number of patients treated with cyclosporine in severe UC. Results showed that almost $18 \%$ of patients presented infections, sometimes serious, paresthesias were reported in $9 \%$, and death caused by opportunistic infections or acute allergic reactions was confirmed in $3.5 \%$ patients. ${ }^{25}$

When a response to cyclosporine is seen after seven days, e.v. administration can be suspended and therapy swopped to oral administration at a dose of 5 $\mathrm{mg} / \mathrm{kg} /$ die during the gradual reduction of steroid. In spite of these encouraging results, the long-term efficacy does not seem to be so positive. In fact, after eight months, approximately $44 \%$ of patients have a severe relapse of disease requiring colectomy. Precisely because of the high frequency of relapse, it has recently been proposed to start an immunosuppressive treatment with azathioprine or 6-mercaptopurine as maintenance therapy in patients who have shown clinical remission with cyclosporine.

During combined treatment with 2 or more immunosuppressive drugs, prophylaxis is recommended to prevent pneumonia from Pneumocystis with comitroxazole trimetoprim for 2-3 days a week.

The use of cyclosporine requires setting up reference centers where hemochromocytometric tests can be carried out to monitor drug toxicity and where the patient can be followed by both gastroenterologists and members of the Surgical Unit. Blood levels of cyclosporine must be maintained at $150-300 \mathrm{ng} / \mathrm{mL}$, monitored by high-performance liquid chromatography. It is also important to determine the blood cholesterol and magnesium concentrations before starting cyclosporine treatment in order to reduce the risk of tonic-clonic seizures.

Recently, Actis and colleagues have compared e.v. cyclosporine $2 \mathrm{mg} / \mathrm{kg} /$ die with oral administration with respect to cyclosporine micro-emulsion at a dose of $5 \mathrm{mg} / \mathrm{kg} / \mathrm{die}$. The oral formulation was shown to be superior in terms of efficacy but was responsible for major side effects with respect to parenteral formulation. Also the ECCO guidelines suggest the use of cyclosporine in the treatment of active severe $\mathrm{UC}$, but the role of this therapeutic approach in the long term still needs to be clarified.

\section{Infliximab}

Anti-TNF-alfa monoclonal antibodies have been shown to help induce and maintain remission in the treatment of steroid-dependent Crohn's disease or disease-related fistulas. The first open clinical experiences have confirmed the efficacy of infliximab also in active UC. First, $\mathrm{Chey}^{26}$ treated 16 patients with active steroid-refractory UC with a single or double infusion of infliximab.

Clinical, endoscopic and histological improvement was observed in 14 of 16 patients (88\%) after infliximab treatment. Surgical intervention was avoided in 6 candidates for surgery (86\%). Clinical remission was maintained in 14 of 16 patients $(88 \%)$ for at least four months and in 4 patients of $16(25 \%)$ for 7-10 months. Most of the patients treated with infliximab were able to completely interrupt steroid treatment.

Recently, Kohn and colleagues ${ }^{27}$ presented an open study on efficacy of infliximab in patients with active steroid-dependent UC. Thirteen patients were enrolled after 7-10 days of steroid treatment (methylprednisolone $60 \mathrm{mg} / \mathrm{die}$ ) and treated with a single infusion of infliximab $5 \mathrm{mg} / \mathrm{kg}$. Ten patients (77\%) had a clinical response within 2-3 days after the infusion. Nine of 10 patients maintained clinical remission in an average follow-up of 10.1 months without the need for steroids. Three controlled clinical studies have evaluated the efficacy of infliximab in severe UC. First, Jarnerot in Denmark and Sweden compared a single infusion of 5 $\mathrm{mg} / \mathrm{kg}$ of infliximab versus placebo in patients with severe $\mathrm{UC}$ after seven days of e.v. maximum steroid treatment. Forty-five patients were randomized into two groups and the number of colectomies or deaths was evaluated after 90 days of treatment. Secondary end points were clinical and endoscopic remission in patients who did not require surgery.

At the end of the study, the cumulative percentage of patients who had not undergone surgery were $71 \%$ in the group treated with infliximab and $33 \%$ in the placebo group ( $\mathrm{P}=0.0038)$. No deaths were reported during the study and minor side effects were observed ${ }^{28}$ In the same period, two large studies were carried out on UC patients with chronically active moderate or severe steroid-dependent disease and refractory to immunosuppressive or mesalamine therapy. Also in these patients (candidates for surgery) treatment with infliximab was capable of inducing clinical improvement in approximately $70 \%$ of pa- 
tients and cure of endoscopic lesions in 62\% of patients after eight weeks of therapy. ${ }^{29}$

The European ECCO guide-lines included infliximab among the rescue therapies (LE GR) of active severe forms of UC that are non-responsive to traditional therapy, giving it the same status as cyclosporine. Nevertheless, clinical studies available so far show a wide variability in results in terms of efficacy of infliximab in reducing the need for cholectomy. ${ }^{30-33}$ Further controlled clinical studies are, therefore, needed in this setting. ${ }^{5}$

There is still not sufficient evidence to determine which is the drug of choice, cyclosporine or infliximab, in cases of failure of steroid treatment. A study is close to completion that directly compares the 2 drugs. But until these results are available, physicians must choose which drug to use according to personal experience. Therapeutic flow chart in severe ulcerative colitis is available in Figure 1.

\section{Conclusions}

Corticosteroids remain in the front line of treatment for severe ulcerative colitis. Recognition of the negative prognostic factors allows therapy with infliximab or a surgical approach to be adopted without delay. Infliximab has been shown to be efficacious also in inducing

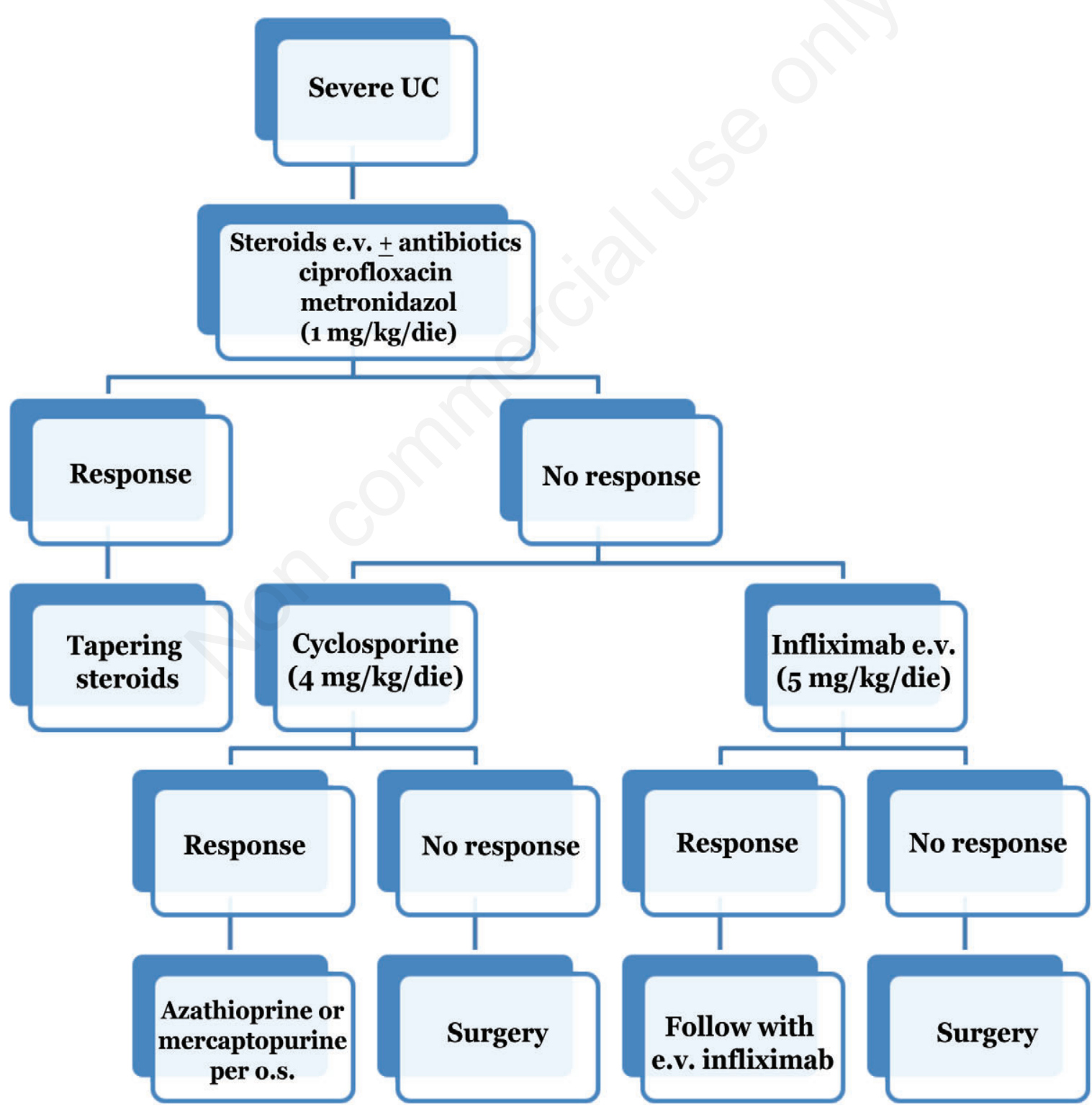

Figure 1. Therapy flow chart for severe ulcerative colitis (UC). e.v., endovenous; o.s., oral somministration. 
and maintaining remission free from steroids in steroiddependent patients who have not responded to therapy with traditional immunomodulatory drugs.

\section{References}

1. Truelove SC, Witts LJ. Cortisone in ulcerative colitis: preliminary report on a therapeutic trial. BMJ 1954; 2:375-8.

2. Truelove SC, Jewell DP. Intensive intravenous regimen for severe attacks of ulcerative colitis. Lancet 1974;I: 1067-70.

3. Baron JH, Conell AM, Lennard-Jones JE. Variation between observers in describing mucosal appearance in proctocolitis. Br Med J 1964;1:89-92.

4. Carbonnel F, Lavergne A, Lémann $M$, et al. Colonoscopy of acute colitis: a safe and reliable tool for assessment of severity. Dig Dis Sci 1994;39:1550-7.

5. Dignass AG, Van Assche JO, Lindsay, et al. The second European evidence-based consensus on the diagnosis and management of Crohn's disease: current management. J Crohn Colitis 2010;4:28-62.

6. Orlando A, Armuzzi A, Papi C, et al. The Italian Society of Gastroenterology (SIGE) and the Italian Group for the study of Inflammatory Bowel Disease (IG-IBD) Clinical Practice Guidelines: The use of tumor necrosis factor-alpha antagonist therapy in inflammatory bowel disease. Dig Liver Dis 2011;43:1-20.

7. Travis SP, Farrant JM, Ricketts C, et al. Predicting outcome in severe ulcerative colitis. Gut 1996;38:905-10.

8. Lennard-Jones JE, Ritchie JK, Hilder W, Spicer CC. Assessment of severity in colitis: a preliminary study. Gut $1975 ; 16: 579-84$

9. Caprilli R, Vernia P, Latella G, Torsoli A. Early recognition of toxic megacolon. J Clin Gastroenterol 1987; 9:160-4.

10. Chew CN, Nolan DJ, Jewell DP. Small bowel gas in severe ulcerative colitis. Gut 1991;32:1535-7.

11. Edward FC, Truelove SC. The course and prognosis of ulcerative colitis. Gut 1963;4:299-315.

12. Jarnerot G, Rolny P, Sandberg-Gertzen H. Intensive intravenous treatment of ulcerative colitis. Gastroenterology 1985;89:1005-13.

13. Bossa F, Fiorella S, Caruso N, et al. Continuous infusion versus bolus administration of steroids in severe attacks of ulcerative colitis: a randomized, double-blind trial. Am J Gastroenterol 2007;102:601-8.

14. Dickinson RJ, Ashton MG, Axon AT, et al. Controlled trial of intravenous hyperalimentation and total bowel rest as an adjunct to the routine therapy of acute colitis. Gastroenterology 1980;79:1199-204.

15. Chapman RW, Selby WS, Jewell DP. Controlled trial of intravenous metronidazolo as an adjunt to corticosteroids in severe ulcerative colitis. Gut 1986;27:1210-2.

16. Mantzaris GJ, Petraki K, Archavlis E, et al. A prospective randomized controlled trial of intravenous ciprofloxacin as an adjunct to corticosteroids in acute, severe ulcerative colitis. Scand J Gastroenterol 2001; 36:971-4
17. Dickinson RJ, O'Connor HJ, Pinder I, et al. Double blind controlled trial of oral vancomycin as adjunctive treatment in acute exacerbation of idiopathic colitis. Gut 1985;26:1380-4.

18. Burke DA, Axon AT, Clayden SA, et al. The efficacy of tobramycin in the treatment of ulcerative colitis. Aliment Pharmacol Ther 1990;4:123-9.

19. Gionchetti P, Rizzello F, Ferrieri A, et al. Rifaximin in patients with moderate or severe ulcerative colitis refractory to steroid treatment: a double blind, placebo controlled trial. Dig Dis Sci 1999;44:1220-1.

20. Lichtiger S, Present D, Kornbluth A, et al. Cyclosporine in severe ulcerative colitis refractory to steroid therapy. N Engl J Med 1994;330:1841-5.

21. D'Haens G, Lemmes L, Geboes K, et al. Intravenous cyclosporine versus intravenous corticosteroids as single therapy for severe attaks of ulcerative colitis. Gastroenterology 2001;120:1323-9.

22. Van Assche G, D'Haens G, Noman M, et al. Randomized, double-blind comparison of $4 \mathrm{mg} / \mathrm{kg}$ versus $2 \mathrm{mg} / \mathrm{kg}$ intravenous cyclosporine in severe ulcerative colitis. Gastroenterology 2003;125:1025-31.

23. Carbonnel F, Boruchowicz A, Duclos B, et al. Intravenous cyclosporine in attacks of ulcerative colitis: short-term and long-term responses. Dig Dis Sci 1996; 41:2471-6.

24. Sands BE, Tremaine WJ, Sandborn WJ, et al. Infliximab in the treatment of severe, steroid-refractory ulcerative colitis: a pilot study. Inflamm Bowel Dis 2001;7:83-8.

25. Arts J, D'Haens G, Zeegers M, et al. Long-term outcome of treatment with intravenous cyclosporine in patients with severe ulcerative colitis. Inflamm Bowel Dis 2004; 10:73-8.

26. Chey W. Infliximab for patients with refractory ulcerative colitis. Inflamm Bowel Dis 2001;1:s30-3.

27. Kohn A, Prantera C, Pera A, et al. Anti-tumor necrosis factor alpha (infliximab) in the treatment of severe ulcerative colitis: result of an open study on 13 patients. Dig Liv Dis 2002;34:626-30.

28. Jarnerot G, Hertervig E, Friis-Liby I, et al. Infliximab as rescue therapy in severe to moderately severe ulcerative colitis: a randomized, placebo-controlled study. Gastroenterology 2005;128:1805-11.

29. Rutgeerts P, Sandborn WJ, Feagan BG, et al. Infliximab in induction and maintenance therapy for ulcerative colitis. N Engl J Med 2005;353:2462-76.

30. Lawson MM, Thomas AG, Akobeng AK. Tumour necrosis factor-alpha blocking agents for induction of remission in ulcerative colitis. Cochrane Database Syst Rev 2006;3:CD005112.

31. Gisbert JP, Gonzàlez-Lama Y, Maté J. Systematic review: infliximab therapy in ulcerative colitis. Aliment Pharmacol Ther 2007;25:19-37.

32. Sandborn WJ, Rutgeerts P, Feagan BG, et al. Colectomy rate comparison after treatment of ulcerative colitis with placebo or Infliximab. Gastroenterology 2009;137: 1250-60.

33. Jarnerot G, Hertervig E, Friis-Liby I, et al. Infliximab as rescue therapy in severe to moderately severe ulcerative colitis: a randomized, placebo-controlled study. Gatsroenterology 2005;128:1805-11. 